Canadian

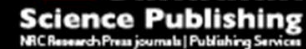

Canadian Journal of Chemistry Revue canadienne de chimie

\title{
Magnetic alginate beads with high basic dye removal potential and excellent regeneration ability
}

\begin{tabular}{|c|c|}
\hline Journal: & Canadian Journal of Chemistry \\
\hline Manuscript ID & cjc-2016-0641.R1 \\
\hline Manuscript Type: & Article \\
\hline Date Submitted by the Author: & 24-Mar-2017 \\
\hline Complete List of Authors: & $\begin{array}{l}\text { Elwakeel, Khalid; Faculty of Science, Port-Said University, Environmental } \\
\text { Science Department; Faculty of science, University of Jeddah, Chemistry } \\
\text { Department } \\
\text { El-Bindary, A.; Chemistry Department, Faculty of Science, Mansoura } \\
\text { University, Demiatta, Egypt, Chemistry Department; } \\
\text { El-Sonbati, Adel; Chem. Dept., Fac. of Sci., Mansoura University, Demiatta, } \\
\text { Egypt, Chem. Dept. } \\
\text { Hawas, Ahmed; Faculty of Science, Damietta University, Damietta 34517, } \\
\text { Egypt, Chemistry Department }\end{array}$ \\
\hline $\begin{array}{r}\text { Is the invited manuscript for } \\
\text { consideration in a Special } \\
\text { Issue?: }\end{array}$ & N/A \\
\hline Keyword: & Adsorption, Kinetics, Thermodynamics, Regeneration, Alginate \\
\hline
\end{tabular}




\title{
Magnetic alginate beads with high basic dye removal potential and excellent regeneration ability
}

\author{
K.Z. Elwakeel $^{\text {a,b }}$, A.A. El-Bindary ${ }^{c_{*}}$, A.Z. El-Sonbati ${ }^{\mathrm{c}}$, A.R. Hawas ${ }^{\mathrm{c}}$ \\ ${ }^{a}$ Chemistry Department, Faculty of science, University of Jeddah, Jeddah, Saudi Arabia \\ ${ }^{b}$ Environmental Science Department, Faculty of Science, Port-Said University, Port-Said, Egypt \\ ${ }^{c}$ Chemistry Department, faculty of Science, Damietta University, Damietta 34517, Egypt \\ *Corresponding author: E-mail address: abindary@yahoo.com (A.A. El-Bindary).
}

\begin{abstract}
The adsorption of crystal violet dye (CV) onto magnetic alginate composite (MAlg) from aqueous solutions was studied. Experiments were carried out as function of contact time, dosage, temperature, $\mathrm{pH}$ and $\mathrm{CV}$ concentration in the solutions. Optimum $\mathrm{CV}$ uptake was observed at equilibrium $\mathrm{pH} 7$ and most of the $\mathrm{CV}$ was sorbed within $30 \mathrm{~min}$. The equilibrium adsorption data were analyzed using two common adsorption models: Langmuir and Freundlich. The results revealed that Langmuir isotherm fit the experimental results well. The maximum adsorption capacity obtained from Langmuir isotherm equation was $0.113 \mathrm{mmol}$ $\mathrm{g}^{-1}$ at $298 \pm 1 \mathrm{~K}$. The kinetics adsorption of $\mathrm{CV}$ onto MAlg composite was investigated using the pseudo first order and pseudo second order kinetic models. The results showed that the adsorption of $\mathrm{CV}$ onto MAlg composite followed pseudo second order kinetic model. Thermodynamic data indicated that adsorption process is endothermic and spontaneous reaction. Due to their outstanding adsorption capacities, MAlg composite is an excellent adsorbent for the removal of $\mathrm{CV}$. The Composite regeneration was greater than $98.6 \%$ with $0.01 \mathrm{M} \mathrm{HCl}$, and MAlg composite could be repeatedly utilized for $\mathrm{CV}$ removal with negligible loss in sorption capacity.
\end{abstract}

Keywords: Alginate; Adsorption; Kinetics; Thermodynamics; Regeneration 


\section{Introduction}

Synthetic dyes are extensively used in paper, textile, food, and pharmaceutical industries. About 40,000-50,000 tons of dyes are continuously entering the water systems due to improper processing and dying methods from these industries [1]. Many of the dyes are extremely toxic. Among various dyes, Crystal violet (CV), a synthetic basic cationic dye imparts violet color in aqueous solution. The cationic dyes are more toxic than the anionic dyes [2] as these can easily interact with negatively charged cells membrane surfaces, and can enter into cells and concentrate in cytoplasm [3]. CV is a typical triphenylmethane dye, which is widely used in textile dyeing industries, as a biological stain, dermatological agent, veterinary medicine, additive to poultry feed to inhibit propagation of harmful bacteria [4]. $\mathrm{CV}$ is toxic to mammalian cells and also a mutagen, mitotic poison [5] and a proven potent carcinogen [6]. It is responsible for moderate eye irritation, causing painful sensitization to light. It can cause permanent injury to the cornea and conjunctiva [7]. Inhalation of CV may cause irritation to the respiratory tracks, vomiting, diarrhea, pain, headache, and dizziness. Long term exposure may cause damage to the mucous membrane and gastrointestinal tract [8]. It is also extensively used in textile dying and paper printing. It is a mutagen and mitotic poison. Various treatment technologies like adsorption [9-13], photo degradation [14-18], coagulation flocculation [19], chemical oxidation [20,21], electrochemical oxidation [22], biological process [23] etc. are available for the removal of dye from the wastewater. Among these approaches, adsorption is regarded as an easy, economic and desirable process due to its high efficiency and ability to separate wide range of pollutants from industrial effluents [24] Alginate is one of the most extensively investigated biopolymers for removal of pollutants from aqueous solution as it is inexpensive, non-toxic and efficient. It is a natural poly saccharide extracted from brown sea weeds. Alginate is a very efficient sorbent for metal ions, However, the main drawback of its use as adsorbent is the weak mechanical strength and subsequently its weak ability for repeated use [25]. To solve this problem researcher incorporated sodium alginate in nanocomposite hydrogels [26]. The encapsulation of magnetite particles onto alginate beads is a promising solution to overcome this problem. The incorporation of magnetite within an alginate matrix improves its mechanical strength and regeneration ability. Moreover, magnetic nanoparticles can be present as a stable suspension that will not aggregate, thereby allowing uniform distribution in a reaction mixture. Within this framework, the present work focuses on the development of adsorbent combining magnetite within an alginate matrix and investigation of its performance in the removal of 
crystal violet dye from aqueous solution. Here the equilibrium and kinetic behavior of $\mathrm{CV}$ adsorption were investigated onto magnetic alginate composite. Effects of different parameters such as $\mathrm{pH}$, dye concentration, contact time, temperature, adsorbent dose on both equilibrium and the rate of adsorption were studied. Isotherms were fitted to the Langmuir, Freundlich, Dubinin-Radushkevich and Temkin models to qualify and quantify sorption sites and evaluate the mobilisation process. The batch contact time method was used to measure the adsorption rate. Kinetic parameters were then evaluated. The adsorbent was tested for its possible ability towards repeated use. The results obtained here will be useful in further applications of MAlg composite in color removal from wastewater.

\section{Materials and methods}

\subsection{Chemicals and reagents}

All materials were commercial reagent grade and used as received without further purification. The reagents used for the preparation of $\mathrm{MAlg}$ were $\mathrm{FeSO}_{4} \cdot 2 \mathrm{H}_{2} \mathrm{O}$ (Aldrich), $\mathrm{FeCl}_{3} \cdot 6 \mathrm{H}_{2} \mathrm{O}$ (Aldrich), ammonium hydroxide (25\% Merck), sodium alginate (Aldrich, with molecular weight of 12,000-40,000) and calcium chloride (Prolabo). Demineralized water was used in all experiments. Crystal violet dye (CV) was purchased from Sigma-Aldrich chemical Co. (Scheme 1). CV stock solution of $500 \mathrm{mg} \mathrm{L}^{-1}$ for desired concentration was prepared.<smiles>CN(C)c1ccc(C(=C2C=CC(=[N+](C)C)C=C2)c2ccc(N(C)C)cc2)cc1</smiles>

Scheme 1: Chemical structure of crystal violet dye.

\subsection{Synthesis of magnetic alginate composite}


The MAlg composite was synthesized using in situ precipitation of $\mathrm{FeSO}_{4}$ and $\mathrm{FeCl}_{3}$ in alkaline solution in the presence of sodium alginate. Initially, in a beaker, $30 \mathrm{~mL}$ of ammonium hydroxide solution was mixed with $20 \mathrm{~mL}$ of demineralized water to obtain an alkaline solution (7.94 mol NH $\mathrm{L}^{-1}$ ). In another beaker, $9.36 \mathrm{~g} \mathrm{FeCl}_{3}$ and $3.44 \mathrm{~g} \mathrm{FeSO}_{4}$ were dissolved in $100 \mathrm{~mL}$ demineralized water and then mixed with $40 \mathrm{~mL}$ of sodium alginate aqueous solution $(2 \%, \mathrm{w} / \mathrm{w})$ at $298 \mathrm{~K}$ for $60 \mathrm{~min}$ under magnetic stirring. The resultant mixture was slowly dropped into the alkaline solution at $333 \mathrm{~K}$ under $\mathrm{N}_{2}$ atmosphere and vigorous mechanical stirring. The resulting black precipitate was left to react for $70 \mathrm{~min}$. Then, the obtained precipitate was separated in a magnetic field and washed for three times with demineralized water to remove impurities and excess of sodium alginate not bound to $\mathrm{Fe}_{3} \mathrm{O}_{4}$ particles. It should be noted that coating of particles may occurs by electrostatic attraction between carboxylate groups of sodium Alginate, $\mathrm{Fe}^{2+}$ and $\mathrm{Fe}^{3+}$ ions of $\mathrm{Fe}_{3} \mathrm{O}_{4}$ particles. Magnetic calcium alginate beads were prepared by stirring the obtained black precipitate in $2 \% \mathrm{CaCl}$ solution for $24 \mathrm{~h}$ at $303 \mathrm{~K}$. The sorbent thus obtained was washed well with distilled water to remove the excess $\mathrm{CaCl}_{2}$. Finally, MAlg particles were dried at $353 \mathrm{~K}$ under vacuum condition for $24 \mathrm{~h}$ to obtain final product.

\subsection{Characterization of MAlg}

The structure of the synthesized MAlg was examined by X-ray diffraction measurement $(\mathrm{XRD})$ is recorded on X-ray diffract meter in the range of diffraction angle $2 \theta=5-80^{\circ}$. This analysis is carried out using $\mathrm{CuK} \alpha 1$ radiation $(\lambda=1.540598 \AA)$. The applied voltage and the tube current are $40 \mathrm{KV}$ and $30 \mathrm{~mA}$, respectively. The diffraction peaks are indexed and the lattice parameters are determined with the aid of CRYSFIRE computer program [27]. In order to confirm the structure of magnetic alginate composite were examined in dried $\mathrm{KBr}$ powder by recording the infrared spectra over the range of $4000-400 \mathrm{~cm}^{-1}$ using a Fourier transform infrared (FTIR) spectrophotometer (Jasco FTIR-4100 spectrophotometer). Thermal analysis of the risen are carried out using a Shimadzu thermo gravimetric analyzer under nitrogen atmosphere with heating rates of $10-15{ }^{\circ} \mathrm{C} / \mathrm{min}$ over a temperature range from room temperature up to $1073 \mathrm{~K}$. Scanning Electron Microscope (SEM) are carried out using JEOL JSM 6510 lv.

\subsection{Sorption experiments}


A stock solution $\left(1 \times 10^{-3} \mathrm{M}\right)$ of $\mathrm{CV}$ dye was prepared in distilled water. The other solutions were obtained by dilution of the stock solution with distilled water just prior experiments. For the study of $\mathrm{pH}$ effect $25 \mathrm{~mL}$ of $2 \times 10^{-4} \mathrm{M}$ solution at different $\mathrm{pH}$ values (in the range 1-9) were mixed with $50 \mathrm{mg}$ of sorbent (dried weight) for $2 \mathrm{~h}$, and the stirring speed was maintained at $150 \mathrm{rpm}$ using a reciprocal agitator, Rota bit, J.P. Selecta (Spain). The pH values were adjusted by addition of $0.1,0.01 \mathrm{~N} \mathrm{HCl}$ and $0.1,0.01 \mathrm{~N} \mathrm{NaOH}$ solutions and measured by using a $\mathrm{pH}$ meter (Aqualytic AL15). Samples were collected and filtrated through magnetic separation and the filtrate was analyzed for residual CV concentration using Perkin-Elmer AA800 spectrophotometer (Model AAS) at wavelength of $590 \mathrm{~nm}$. The $\mathrm{pH}$ was not controlled during the sorption but the final $\mathrm{pH}$ was systematically recorded.

For sorption isotherms $50 \mathrm{mg}$ of sorbent (m) were mixed with $25 \mathrm{~mL}$ (V) of CV solutions at different initial concentrations $\left(\mathrm{C}_{0}\right.$, ranging between $8 \times 10^{-5}$ and $\left.8 \times 10^{-4} \mathrm{M}\right)$ for $2 \mathrm{~h}$. The $\mathrm{pH}$ of the solutions was initially set at 7 . After solid/liquid separation, the residual concentration

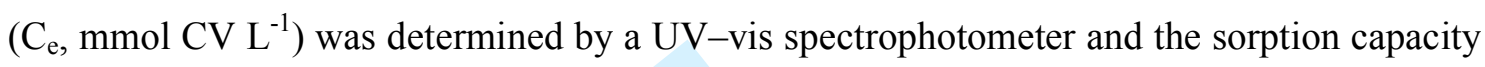
$\left(\mathrm{q}_{\mathrm{e}}, \mathrm{mmol} . \mathrm{g}^{-1}\right)$ was determined by the mass balance equation:

$q_{e q}=\frac{\left(C_{0}-C_{e}\right) V}{m}$

Where $\mathrm{C}_{0}$ and $\mathrm{C}_{\mathrm{e}}$ is the initial and equilibrium concentration of metal ion in solution (M), respectively, $\mathrm{V}$ is the volume of solution $(\mathrm{L})$ and $\mathrm{m}$ the mass of sorbent $(\mathrm{g})$.

For uptake kinetics $300 \mathrm{mg}$ of sorbent were mixed with $150 \mathrm{~mL}$ of $\mathrm{CV}$ solutions $\left(\mathrm{C}_{0}: 2 \times 10^{-4}\right.$ M) at $\mathrm{pH}$ 7. Samples $(1 \mathrm{~mL})$ were collected (the sorbent being magnetically separated) at fixed times and the residual concentrations were determined by UV-VIS spectrophotometer. The agitation speed was set at $150 \mathrm{rpm}$ while the temperature was maintained at $298 \pm 1 \mathrm{~K}$. The sorbed amount of CV per unit weight of the sorbent at time $\mathrm{t}\left(\mathrm{q}(\mathrm{t}), \mathrm{mmol} \mathrm{CV} \mathrm{g}{ }^{-1}\right.$ ), was calculated from the mass balance equation (taking into account the decrement in the volume of the solution) according:

$q(t)=\sum_{i=1}^{n} \frac{\left(C(t)_{(i-1)}-C(t)_{(i)}\right) \times V(t)_{(i-1)}}{m}$

where $C(t)_{(i)}(M)$ is the $C V$ concentration of the withdrawn sample number $i$ at time $t$ and $\mathrm{C}(\mathrm{t})_{(0)}=\mathrm{C}_{0}, \mathrm{~V}(\mathrm{t})_{(\mathrm{i})}(\mathrm{mL})$ is the volume of the solution in the flask at sample number $\mathrm{i}$ and 
time $t$, and $\mathrm{m}$ is the mass of the sorbent in the flask. Here $\mathrm{V}(\mathrm{t})_{(\mathrm{i})}-\mathrm{V}(\mathrm{t})_{(\mathrm{i}-1)}$ equals $1 \mathrm{~mL}$ (the sample volume).

The effect of temperature on the adsorption of CV was carried out in the $25 \mathrm{~mL}$ of dye solutions $\left(2 \times 10^{-4} \mathrm{M}, \mathrm{pH} 7\right)$ with $50 \mathrm{mg}$ of adsorbent for $30 \mathrm{~min}$ at various temperatures (293, 298, 303, 308, 313 and $318 \mathrm{~K})$.

The effect of sorbent dose on $\mathrm{CV}$ dye removal was carried out in the $25 \mathrm{~mL}$ of dye solutions $\left(2 \times 10^{-4} \mathrm{M}, \mathrm{pH} 7\right)$ with $0.01,0.02,0.03,0.04,0.05,0.06,0.07,0.08,0.09$ and $0.1 \mathrm{~g}$ of adsorbent at $298 \pm 1 \mathrm{~K}$ for $30 \mathrm{~min}$.

Regeneration experiments were performed by contact of $50 \mathrm{mg}$ of the sorbent with $25 \mathrm{~mL}$ of $2 \times 10^{-4} \mathrm{M} \mathrm{CV}$ at $\mathrm{pH} 7$ for $30 \mathrm{~min}$. The amount of dye sorbed (and the sorption capacity) was determined by the mass balance (Eq. 1). The solution was magnetically decanted and the adsorbent was washed by distilled water. The loaded sorbent was mixed with $25 \mathrm{~mL}$ of 0.01 $\mathrm{M} \mathrm{HCl}$ for $30 \mathrm{~min}$. The regenerated sorbent was magnetically decanted, then carefully washed by alkaline solution $(0.001 \mathrm{M} \mathrm{NaOH})$ and distilled water for reuse in the second run. The regeneration efficiency (RE, \%) was calculated according to the following equation:

$\mathrm{RE} \%=\frac{\text { Amount of adsorbed CV }(\mathrm{mmol}) \text { at run }(\mathrm{n}+1)}{\text { Amount of adsorbedCV }(\mathrm{mmol}) \text { at run }(\mathrm{n})} \times 100$

\section{Results and discussion}

\subsection{Characterizations of synthesized MGMA}

\subsubsection{Infrared spectrometry}

The FT-IR spectrum of MAlg composite is presented in Figure SM1 (see Supplementary Material Section). Two absorption bands at 584 and $455 \mathrm{~cm}^{-1}$ corresponding to the $\mathrm{Fe}-\mathrm{O}$ bands in tetrahedral and octahedral sites, confirm the spinel type structure of MAlg particles [28]. Also, the broad band's appearing in the range of $3000-3500 \mathrm{~cm}^{-1}$ can be attributed to stretching vibrations of $\mathrm{O}-\mathrm{H}$ bonds of alginate. The asymmetric and symmetric aliphatic C-H stretching bands were observed at 2900 and $2840 \mathrm{~cm}^{-1}$, respectively. The bands at 1600 and $1402 \mathrm{~cm}^{-1}$ were attributed to the asymmetric and symmetric stretching vibrations of carboxylate groups of alginate, respectively. The bands at 1089 and $1031 \mathrm{~cm}^{-1}$ were attributed to the $\mathrm{C}-\mathrm{O}$ stretching vibration of pyranosyl ring and the $\mathrm{C}-\mathrm{O}$ stretching with contributions 
from $\mathrm{C}-\mathrm{C}-\mathrm{H}$ and $\mathrm{C}-\mathrm{O}-\mathrm{H}$ deformations [29]. However, all of the absorption peaks confirm the coating of alginate onto the surface of magnetite $\left(\mathrm{Fe}_{3} \mathrm{O}_{4}\right)$.

\subsubsection{XRD analysis}

The XRD pattern of the $\mathrm{Fe}_{3} \mathrm{O}_{4}$ is shown in Figure 1. The XRD spectra showed six diffraction peaks of (220), (311), (400), (422), (511), and (440), which confirm the formation of Alg$\mathrm{Fe}_{3} \mathrm{O}_{4}$. These data revealed that the magnetite have inverse type spinel structure [30]. The XRD patterns of $\mathrm{Alg}-\mathrm{Fe}_{3} \mathrm{O}_{4}$ show an amorphous feature by the presence of low intensity broad peak at $2 \theta$ range of $10-20^{\circ}$, which can be attributed to the amorphous shell of alginate on the surface of $\mathrm{Alg}-\mathrm{Fe}_{3} \mathrm{O}_{4}[31,32]$. The averaged crystal size was estimated through full width at half maximum (FWHM) of the strongest reflection of the XRD pattern, using the Scherrer (Eq.1) [33]:

$D c=\frac{K \lambda}{\beta \cos \theta}$

where $\mathrm{k}$ is the shape function (a value of 0.89 is used), $\lambda$ is the X-ray wave length of the radiation, $\beta$ is the full width at half maximum (FWHM) in radians of (311) peak in the $2 \theta$ scale, and $\theta$ is the diffraction angle. According to Scherrer equation, the averaged crystal size was calculated to be about $11.1 \mathrm{~nm}$.

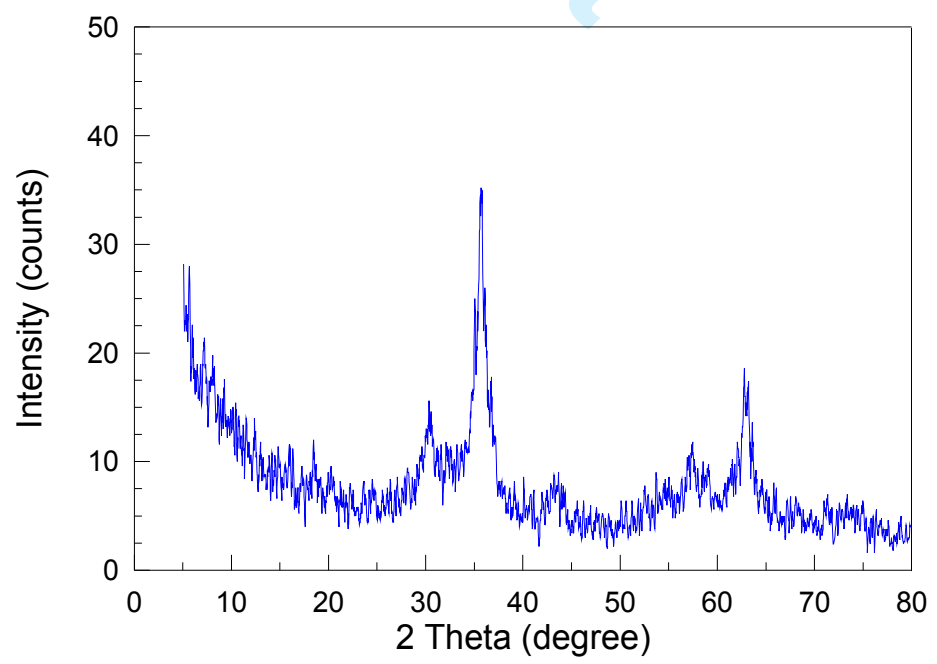

Figure 1: Powder X-ray diffraction (XRD) pattern of MAlg particles (and tentative assignment of peaks). 


\subsubsection{Morphology study}

Scanning electron microscope is useful for determining the particle shape and appropriate size of the adsorbent. In addition, it is important tool for characterizing the surface morphology and fundamental physical properties of the adsorbent surface. Figure 2 shows the SEM analyses of the sorbent before and after CV adsorption. The SEM micrographs of the unloaded MAlg show irregular particles shape with a smooth surface, however, after CV adsorption, the surface of the adsorbent become smoother due to surface covering with dye molecules.

\subsubsection{TGA analysis}

TGA experiments were performed by heating $\mathrm{Fe}_{3} \mathrm{O}_{4}$ particles under nitrogen up to $1087 \mathrm{~K}$ in order to investigate the amount of the alginate bounded onto the surface of $\mathrm{Fe}_{3} \mathrm{O}_{4}$ particles and obtain information on their thermal stability (Figure SM2, see Supplementary Material Section). About $4.0 \mathrm{wt} \%$ weight loss was observed in the first stage (298-450 K) due to the loss of physically absorbed water [33]. In the second stage (450-700 K), weight loss is about $43.0 \mathrm{wt} \%$, which was assigned to thermal degradation of alginate coated onto the surface of $\mathrm{Fe}_{3} \mathrm{O}_{4}$ particles. The weight loss in the third stage $(700-950 \mathrm{~K})$ is about $7 \mathrm{wt} \%$, which may be attributed to further decomposition of alginate residues. Therefore, these results suggest the synthesized $\mathrm{Alg}-\mathrm{Fe}_{3} \mathrm{O}_{4}$ particles are stable below $450 \mathrm{~K}$. The analysis of weight loss at $950 \mathrm{~K}$ showed that the sorbent contains a mineral fraction close to $44 \%$ (magnetite core material). 

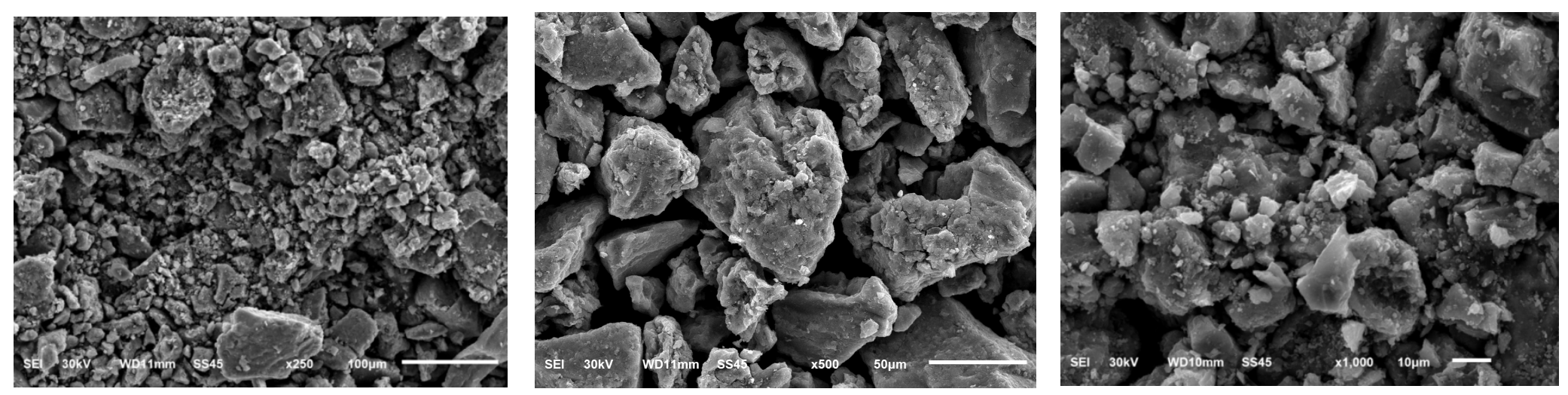

(a)
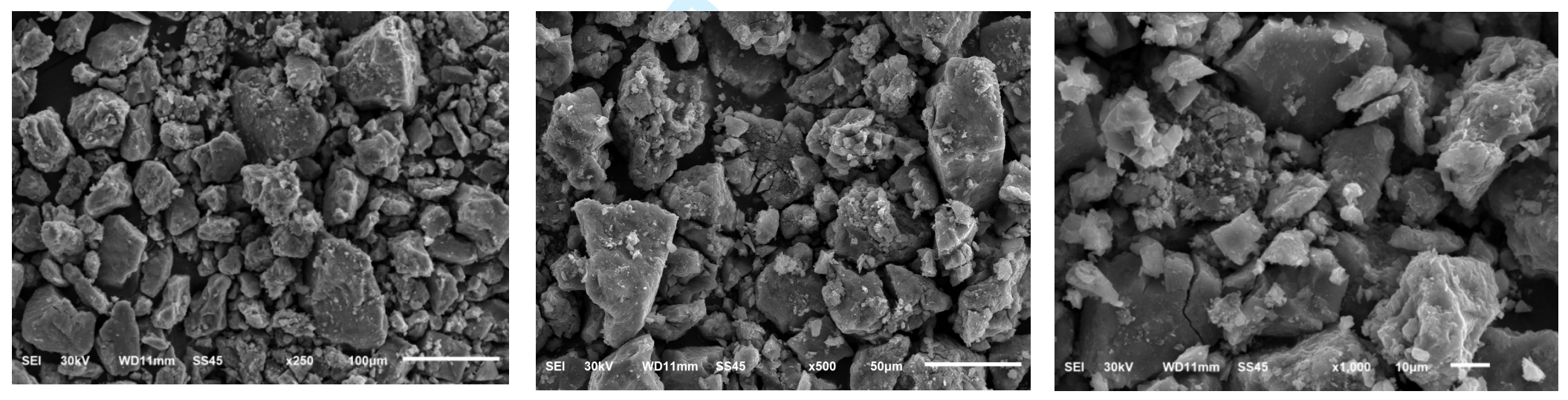

(b)

Figure 2: Scanning electron micrographs of; (a) unloaded MAlg, (b) CV loaded MAlg. 


\subsection{Adsorption analysis}

\subsubsection{Effect of pH on the uptake}

The $\mathrm{pH}$ value of the dye solution is an important factor for determination of the dye adsorption [34].
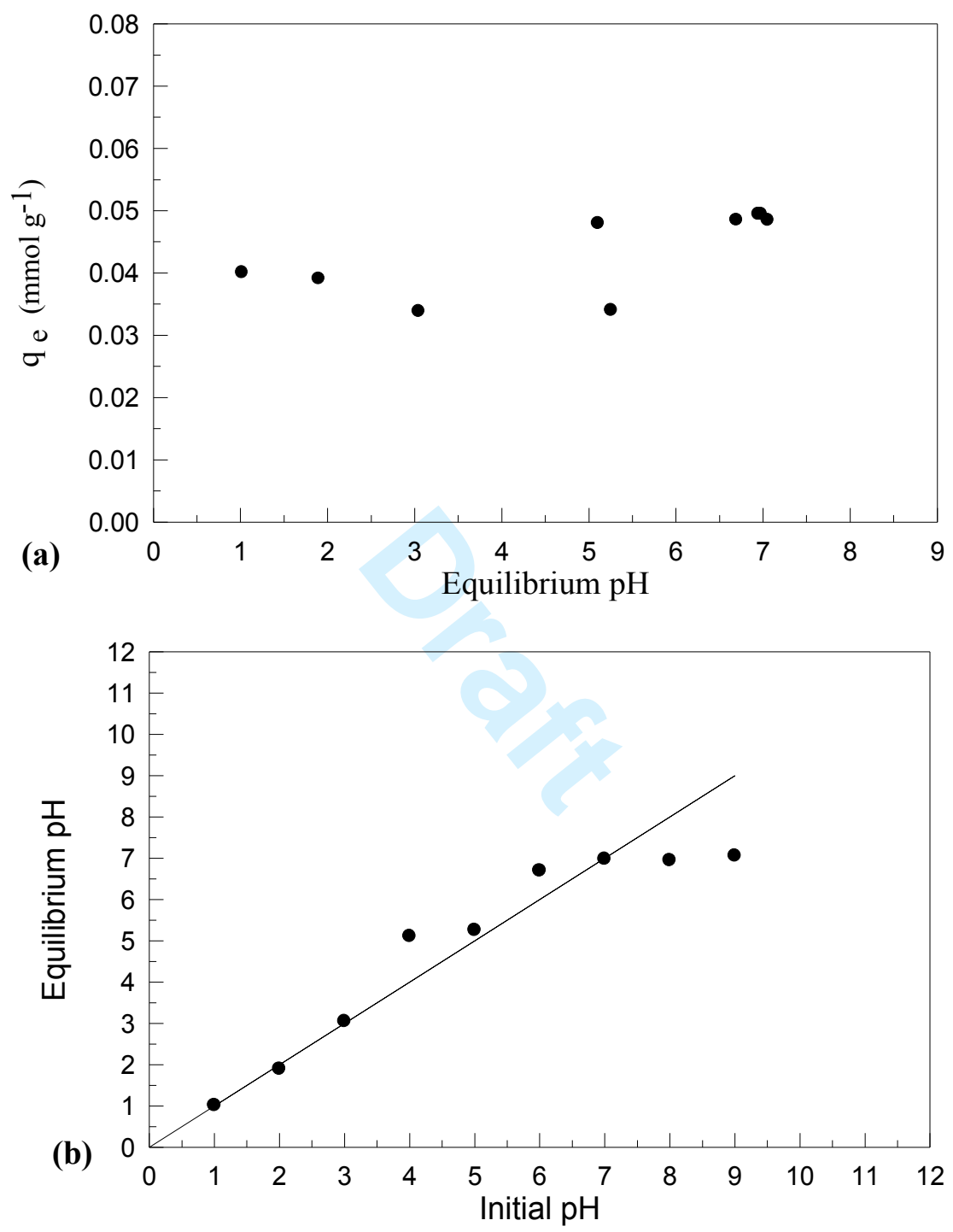

Figure 3: (a) pH effect on CV adsorption using the MAlg adsorbent: (b) the recorded initial and equilibrium (final) $\mathrm{pH}$ : ( $\left.\mathrm{T}: 298 \pm 1 \mathrm{~K} ; \mathrm{C}_{0}: 2 \times 10^{-4} \mathrm{M}\right)$.

This effect can be associated to sorbat speciation, to chemical properties of the adsorbent. The effect of the $\mathrm{pH}$ on the adsorption capacity of CV sorption by MAlg was studied over the initial $\mathrm{pH}\left(\mathrm{pH}_{\mathrm{i}}\right)$ range from (2-9). The results are shown in Figure 3a. The results suggested 
that the adsorption capacity of $\mathrm{CV}$ on MAlg particles was $\mathrm{pH}$ dependent and that maximum $\mathrm{CV}$ removal was obtained equilibrium $\mathrm{pH}\left(\mathrm{pH}_{\mathrm{eq}}\right) 7$ (Equivalent to $\mathrm{pH}_{\mathrm{i}}$ 7-9). Electrostatic interaction could play an important role on $\mathrm{CV}$ adsorption onto MAlg particles at various $\mathrm{pH}$ values. At basic medium, most of the carboxylic and hydroxyl groups in alginates are ionized and interacted with the cationic $\mathrm{CV}$ dye molecules via the strong electrostatic interaction, which is favorable to increase the $\mathrm{CV}$ absorption. Moreover, the negatively charged carboxylate groups present in alginate in basic conditions generate the electrostatic repulsion among the polymer chains. Therefore, the volume expansion in the polymer network can enhance the adsorption of cationic $\mathrm{CV}$ dyes due to increase in the amount of penetrating $\mathrm{CV}$ solution into the alginate structure [35]. In contrast, the relatively weaker CV adsorption under acidic conditions can be attributed to partial protonation of carboxylic groups (carboxylic/carboxylate ratio) of the alginate. Although the $\mathrm{pK}_{\mathrm{a}}$ value of the carboxyl groups of alginate range between 3.4 and 4.4 [36], a appreciable uptake for CV dye at acidic conditions was observed, this may be due to presence of magnetic core in the sorbent which may have additional sorption sites for $\mathrm{CV}$ dye. Some other researchers reported appreciable uptake for CV dye in acidic conditions [37,38].

Figure $3 \mathrm{~b}$ shows the plot of equilibrium $\mathrm{pH}$ versus initial $\mathrm{pH}$. For experiments performed at $\mathrm{pH}_{\mathrm{i}}<7.0$, the equilibrium $\mathrm{pH}\left(\mathrm{pH}_{\mathrm{eq}}\right)$ tended to increase, probably due to the sorption of protons alongside $\mathrm{CV}$ molecule onto the adsorbent surface. In contrast, the adsorption at higher $\mathrm{pH}\left(\mathrm{pH}_{\mathrm{i}}>7.0\right)$ caused a $\mathrm{pH}$ decrease: the removal of alkaline crystal violet molecule might be leads to the increase of the solution $\mathrm{pH}$.

\subsubsection{Adsorption kinetics}

The uptake kinetics of CV using the MAlg sorbent is shown in Figure 4. The kinetic profile is characterized by two phases in the uptake: (a) a first initial step that lasts for about 10 min and counts for more than $96.5 \%$ of total adsorption, (b) a second step that takes about $30 \mathrm{~min}$ and corresponds to a much slower dye accumulation. The initial section of the curve corresponds to a great availability of reactive groups (surface coverage is progressively increasing) and a large concentration gradient between the solution and both the surface and the internal sorption sites. These two conditions may explain the fast initial accumulation of $\mathrm{CV}$ dye. The sorption mainly occurs on the reactive alginate groups covering the surface of the sorbent. The second step, much slower, is controlled by the decrease of the concentration 
Table 1: Kinetic parameters for CV adsorption

\begin{tabular}{|c|c|c|c|c|c|c|c|c|c|c|c|c|c|}
\hline \multicolumn{4}{|c|}{ PFORE } & \multicolumn{4}{|c|}{ PSORE } & \multicolumn{3}{|c|}{ Weber and Morris model } & \multicolumn{3}{|c|}{ Elovich equation } \\
\hline $\mathrm{k}_{1}$ & $\mathrm{q}_{\mathrm{e}, \text { calc }}$ & & & $\mathrm{k}_{2}$ & $\mathrm{q}_{\mathrm{e}, \text { calc }}$ & & & & & & & & \\
\hline (a) & (b) & $\mathrm{R}^{2}$ & $\chi^{2}$ & (c) & (b) & $\mathrm{R}^{2}$ & $\chi^{2}$ & $\mathrm{Ki}(\mathrm{d})$ & $\mathrm{X}$ & $\mathrm{R}^{2}$ & $\begin{array}{c}\alpha \\
\text { (e) }\end{array}$ & $\begin{array}{c}\beta \\
\text { (f) }\end{array}$ & $\mathrm{R}^{2}$ \\
\hline 0.038 & 0.006 & 0.901 & 1.239 & 16.462 & 0.092 & 0.999 & $5.89 \times 10^{-07}$ & 0.00053 & 0.087 & 0.961 & $2.12 \times 10^{23}$ & 704.036 & 0.926 \\
\hline
\end{tabular}

Units: (a): $\min ^{-1}$; (b): $\mathrm{mmol} \mathrm{g}^{-1}$; (c): $\mathrm{g} \mathrm{mmol}^{-1} \min ^{-1}$; (d): $\mathrm{mmol} \mathrm{g}^{-1} \min ^{0.5}$; (e): $\mathrm{mmol} \mathrm{g}^{-1} \mathrm{~min}^{-1}$; (f): $\mathrm{g} \mathrm{mmol}^{-1}$. 


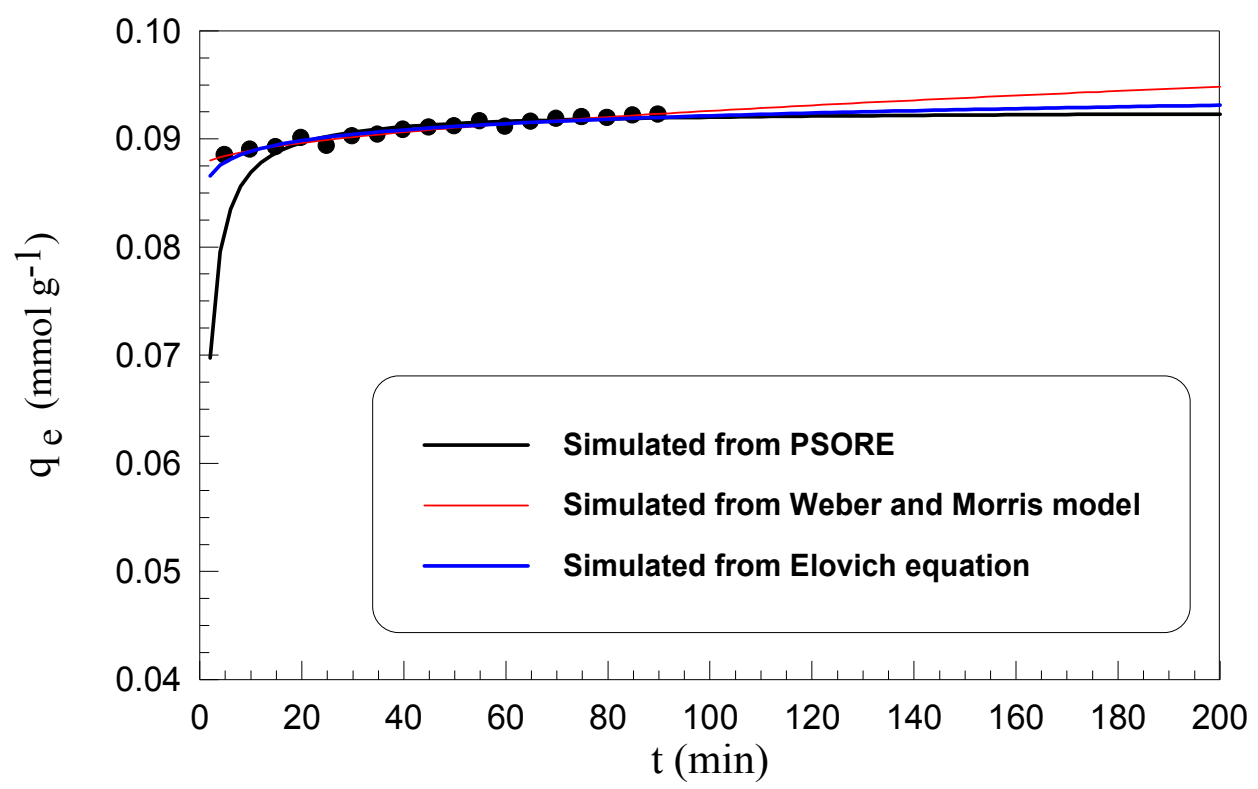

Figure 4: CV uptake kinetics using the MAlg adsorbent: (pH 7; T: $\left.298 \pm 1 \mathrm{~K} ; \mathrm{C}_{0}: 2 \times 10^{-4} \mathrm{M}\right)$.

gradient and by the resistance to intraparticle diffusion and requires much longer time for reaching the equilibrium (i.e., about $90 \mathrm{~min}$ ).

Actually the binding kinetics is controlled by a series of mechanisms including: (a) the bulk diffusion, (b) the resistance to film diffusion (or external diffusion), (c) the resistance to intraparticle diffusion, and (d) the proper reaction rate (chemical reaction rate) [39]. Usually a sufficient agitation allows neglecting the resistance to bulk diffusion and minimizes the resistance to film diffusion whose contribution in the control of uptake kinetics is mainly significant within the first minutes of contact. Experimental data have been modeled using simplified conventional equations to fit kinetic profiles and make possible the comparison of kinetic parameters for the two sorbents. Hence, the kinetics of CV sorption on the MAlg sorbent was analyzed using the pseudo-first order rate equation (PFORE) [40], the pseudosecond order rate equation (PSORE) [41], the simplified resistance to intraparticle diffusion equation [42] and the Elovich equation [43]. These models and their linear forms are reported in Table SM1 (see Supplementary Material Section), where $\mathrm{K}_{1}$ is the pseudo-first order rate constant $\left(\min ^{-1}\right)$ of adsorption and $\mathrm{q}_{\mathrm{e}}$ and $\mathrm{q}(\mathrm{t})\left(\mathrm{mmol}\right.$ dye $\left.\mathrm{g}^{-1}\right)$ are the amounts of $\mathrm{CV}$ sorbed at equilibrium and time $\mathrm{t}$, respectively, $\mathrm{k}_{2}$ is the pseudo-second order rate constant $\left(\mathrm{g} \mathrm{mmol}^{-1}\right.$ $\left.\min ^{-1}\right), \mathrm{K}_{\mathrm{i}}$ is the intraparticle diffusion rate $\left(\mathrm{mmol} \mathrm{g}^{-1} \min ^{-0.5}\right), \alpha$ the initial adsorption rate 
( $\left.m m o l \mathrm{~g}^{-1} \mathrm{~min}^{-1}\right)$ and $\beta$ the desorption constant $\left(\mathrm{g} \mathrm{mmol}^{-1}\right)$. The validity of each model is checked by the correlation coefficient associated to the linear fits and $\chi^{2}$ analysis was used to evaluate the best models to describe the metal ion sorption data. $\chi^{2}$ was determined according to Eq. (5).

$$
\chi^{2}=\frac{\left(Q_{\text {exp }}-Q_{c a l}\right)^{2}}{Q_{c a l}}
$$

where $\mathrm{Q}_{\exp }$ and $\mathrm{Q}_{\mathrm{cal}}$ represent the experimental $\mathrm{Q}$ and calculated $\mathrm{Q}$ from the models, respectively. The best models for describing the kinetic data can be selected if $\mathrm{R}^{2}$ is equal to or near 1 and $\chi^{2}$ is as small as possible. Table 1 reports the parameters of the different models for the studied adsorbents. Systematically, the best correlation coefficients were found for the PSORE model; this is confirmed by the plot of experimental data according the linearized forms of these models: (Figure. SM3, see Supplementary Material Section) for PFORE and PSORE, respectively, show a best fit of kinetic profiles by PSORE. In addition, the comparison of equilibrium adsorption capacities for the calculated value and the experimental value are only consistent for the PSORE model: the equilibrium sorption capacities are found close to $0.006 \mathrm{mmol}$ dye $\mathrm{g}^{-1}$. PSORE modeling gave value of $0.092 \mathrm{mmol}$ dye $\mathrm{g}^{-1}$ closer from experimental value $(0.086 \mathrm{mmol}$ dye $\mathrm{g})$ than PFORE. It was more likely to reflect that the rate-determining step might be chemical sorption and that the sorption behavior might involve an ion exchange mechanism.

However, the PSORE describes kinetics data through a global approach, and does not take into account the contribution of diffusion mechanisms in the control of the kinetics. Under these conditions, the kinetic parameters should be considered as apparent rate coefficients. The influence of resistance to intraparticle diffusion has been approached using a simplified model: the so-called Weber and Morris plot (See Table 1). The intraparticle diffusion model provides a more comprehensive approach for defining of adsorption mechanism, and the plot generally allows identifying different successive steps in the global process [42]. The Weber and Morris show linear plot (Figure SM4a, see Supplementary Material Section) does not pass through the origin suggesting that the resistance to intraparticle diffusion is not the sole rate-limiting step: other steps, e.g. resistance to film diffusion and/or reaction rate, are probably involved in the control of uptake kinetics (Figure SM4a, see Supplementary Material Section). In addition the progressive saturation of available and accessible adsorption sites influences the local equilibrium on the surface between surface sorption and 
desorption. The low value of intraparticle rate constant $\left(\mathrm{K}_{\mathrm{i}}\right)$ appearing in Table 1 indicates that the adsorbent is significantly affected by the resistance to intraparticle diffusion.

The Elovich equation was developed for modeling chemisorption processes [43]. Table SM1 (see Supplementary Material Section) displays the model equation and its linearization as well the plots to be used for determining the parameters. The values of $\alpha$ and $\beta$ were determined from the intercept and slope, respectively, of the linear plot of $\mathrm{q}_{\mathrm{t}} v s$. $\ln \mathrm{t}$ (Figure SM4b, see Supplementary Material Section). The values of $\alpha$ for the sorption of CV dye on the modified sorbents are $2.12 \times 10^{23}\left(\mathrm{mmol} \mathrm{g}^{-1} \mathrm{~min}^{-1}\right)$. This value reflects the high affinity and fast kinetics of $\mathrm{CV}$ onto the MAlg sorbent, which may be attributed to the high concentration of active sites on the sorbent surface allowed for reacting with $\mathrm{CV}$ cations. The value of $\beta$ (desorption constant) is found to be $704.03 \mathrm{~g} \mathrm{mmol}^{-1}$. This value is compatible with the levels cited in our previous work [44]. This is another confirmation of the high affinity of the resin for CV cations.

\subsubsection{Adsorption isotherm}

The adsorption isotherms reveal the specific relation between the concentration of adsorbate and the adsorption capacity of an adsorbent at a constant temperature [45]. Adsorption isotherms provide some information on how an adsorption system proceeds, and indicate how molecules of adsorbate interact with adsorbent [45].

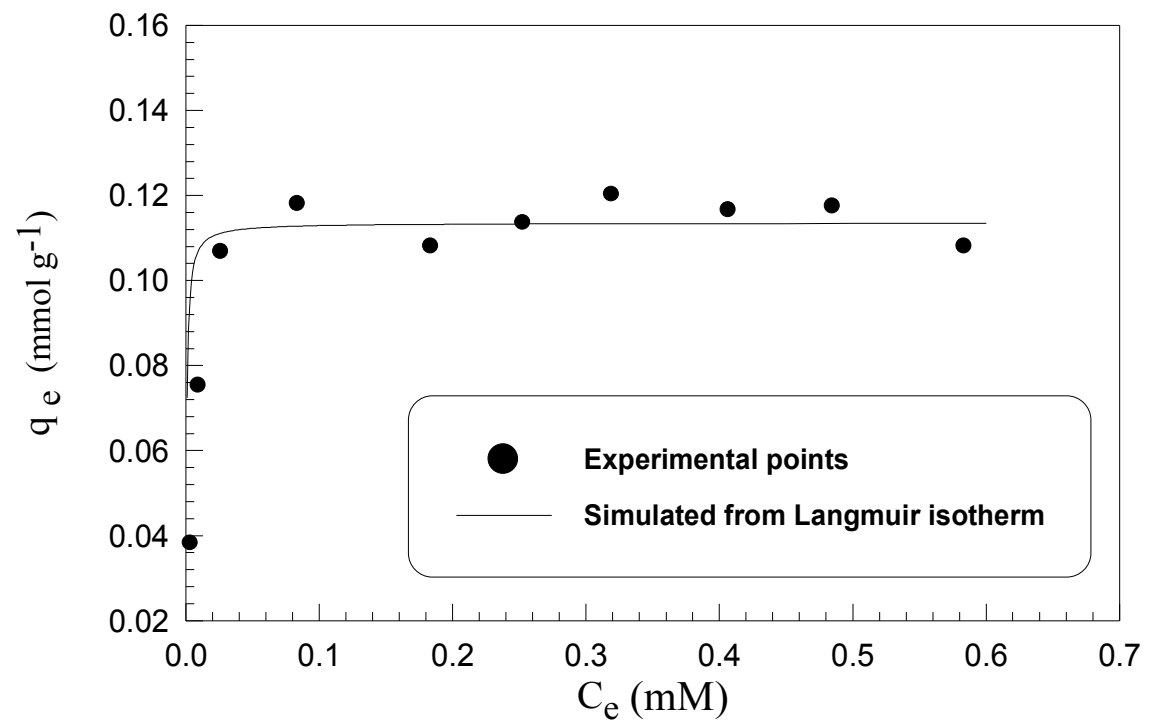

Figure 5: $\mathrm{CV}$ adsorption isotherms of $\mathrm{CV}$ dye onto the MAlg adsorbent (solid line is simulated from Langmuir equation) ( $\mathrm{pH} 7 ; \mathrm{T}: 298 \pm 1 \mathrm{~K})$. 
The Langmuir [46], Freundlich [47], Dubinin-Radushkevich (DR) [48], and Temkin [49] isotherm models were used to explain the sorption of $\mathrm{CV}$ on the MAlg sorbent. The linear and nonlinear forms of the isotherm models are shown in Table SM2 (see Supplementary Material Section), and their parameters are shown in Table 2. where $\mathrm{q}_{\mathrm{e}}$ the adsorbed amount of dye at equilibrium concentration $\left(\mathrm{mmol}^{-1}\right), \mathrm{q}_{\mathrm{m}, \mathrm{L}}$ is the maximum sorption capacity (corresponding to the saturation of the monolayer, mmol.g ${ }^{-1}$ ) and $\mathrm{K}_{\mathrm{L}}$ is the Langmuir binding constant which is related to the energy of sorption $\left(\mathrm{L} \mathrm{mmol}{ }^{-1}\right), \mathrm{C}_{\mathrm{e}}$ is the equilibrium concentration of $\mathrm{CV}$ dye in solution $(\mathrm{M}) \cdot \mathrm{K}_{\mathrm{F}}\left(\mathrm{mmol} \cdot \mathrm{g}^{-1}\right)\left(\mathrm{L} \mathrm{mmol}^{-1}\right)^{1 / \mathrm{n}}$ and $\mathrm{n}$ are the Freundlich constants related to the sorption capacity and intensity, respectively. $\mathrm{K}_{\mathrm{DR}}\left(\mathrm{J}^{2}\right.$ $\left.\mathrm{mol}^{-2}\right)$ is a constant related to the sorption energy, $\mathrm{q}_{\mathrm{DR}}\left(\mathrm{mmol} \mathrm{g}^{-1}\right)$ is the theoretical saturation capacity, $\varepsilon\left(\mathrm{J}^{2} \mathrm{~mol}^{-2}\right)$ is the Polanyi potential. $\mathrm{R}\left(8.314 \mathrm{~J} \mathrm{~mol}^{-1} \mathrm{~K}^{-1}\right)$ is the gas constant, $\mathrm{T}$ is the temperature where the adsorption occurs, $\mathrm{A}_{\mathrm{T}}\left(\mathrm{L} \mathrm{mg}^{-1}\right)$ is the Temkin isotherm constant, $\mathrm{b}_{\mathrm{T}}$ $\left(\mathrm{J} \mathrm{mol}^{-1}\right)$ is Temkin constant in relation to heat of adsorption.

The Langmuir isotherm models were found to be the most suitable models for describing the isotherm for the adsorption of the CV dye into the MAlg sorbent. However, the Freundlich lines deviated from the experimental data points (Figure SM5, see Supplementary Material Section). The isotherm fitting was plotted on the basis of the nonlinear equations using the model constant parameters obtained from the linear equation plot analysis. Via comparison of the $\mathrm{R}^{2}$ values, the Langmuir isotherm resulted in very good fitting, with $\mathrm{R}^{2}$ value of $>0.995$. In addition, the $\mathrm{Q}_{\mathrm{m}}$ calculated from the Langmuir isotherm was close to the experimental $\mathrm{Q}_{\max }$. The isotherm model fittings as shown in Figure 5 also show that the theoretical Langmuir lines were closer to the experimental data. Analysis of isotherm proposed by Dubinin and Radushkevich is presented in Table SM2 (see Supplementary Material Section). This isotherm was developed taking into account the effect of the porous structure of the sorbent, and the energy involved in the sorption process. The Polanyi potential $(\varepsilon)$ given as Eq. (6) [48]:

$$
\varepsilon=\mathrm{RT} \ln \left(1+\frac{1}{\mathrm{C}_{\mathrm{eq}}}\right)
$$

$\mathrm{R}$ is the universal gas constant $\left(8.314 \mathrm{~J} \mathrm{~mol}^{-1} \mathrm{~K}^{-1}\right)$ and $\mathrm{T}$ is the absolute temperature $(\mathrm{K})$. The slope of the plot of $\operatorname{lnq}_{\mathrm{eq}} v s . \varepsilon^{2}$ (Figure SM6 see Supplementary Material Section) gives $\mathrm{K}_{\mathrm{DR}}$ and the intercept yields $Q_{D R}$ (Table SM2, see Supplementary Material Section). The D-R 
constant $\left(\mathrm{K}_{\mathrm{DR}}\right)$ can give valuable information regarding the mean energy of sorption (Ea, $\mathrm{J}$ $\mathrm{mol}^{-1}$ ) by Eq. (7):

$\mathrm{E}_{\mathrm{a}}=\frac{1}{\left(2 K_{D R}\right)^{0.5}}$

The results of D-R isotherm are reported in Table 2. The value of the mean energy of sorption is $9.905 \mathrm{~kJ} \mathrm{~mol}^{-1}$ : this is consistent with the proposed mechanism of chemisorption. Indeed, it is generally admitted that $6 \mathrm{~kJ} \mathrm{~mol}^{-1}$ is the limit energy for distinguishing physical (below $6 \mathrm{~kJ} \mathrm{~mol}^{-1}$ ) and chemical sorption. A comparison of the correlation coefficient values obtained from the Langmuir, Freundlich and D-R isotherm models in Table 2 reveals that the correlation coefficients for the Langmuir isotherm are somewhat higher than those for the Freundlich, D-R isotherm and Temkin models. This result suggests that the binding of dye ions may occur as a monolayer on the surface of the sorbent and that the uptake occurs on a homogenous surface by monolayer sorption. This should be confirmed by experimental observation for confirmation. The uptake can be described in terms of chemisorption as ion exchange mechanism (Protonated amino groups of DETA moiety may be exchanged with anionic dye, depending on the $\mathrm{pH}$ ). The presence the same type of functional groups is comforting the hypothesis of homogeneous surface (or homogeneous energies of sorption). The ranking of the models as follow: Langmuir $>$ Temkin $>$ Dubinin and Radushkevich $>$ Freundlich. 
Table 2: Parameters of the sorption isotherm models Langmuir model Freundlich model Dubinin-Radushkevich (D-R) model Temkin model

\begin{tabular}{|c|c|c|c|c|c|c|c|c|c|c|c|c|c|c|c|}
\hline $\begin{array}{l}\mathrm{q}_{\mathrm{m}, \exp } \\
\text { (a) }\end{array}$ & $\begin{array}{l}\mathrm{q}_{\mathrm{m}, \mathrm{L}} \\
\text { (a) }\end{array}$ & $\begin{array}{l}\mathrm{K}_{\mathrm{L}} \\
\text { (b) }\end{array}$ & $\mathrm{R}^{2}$ & $\chi^{2}$ & $\mathrm{n}$ & $\begin{array}{l}\mathrm{K}_{\mathrm{F}} \\
\text { (c) }\end{array}$ & $\mathrm{R}^{2}$ & $\begin{array}{l}\text { QDR } \\
\text { (a) }\end{array}$ & $\begin{array}{l}\mathrm{K}_{\mathrm{DR}} \\
\text { (d) }\end{array}$ & $\begin{array}{c}\mathrm{Ea} \\
\left(\mathrm{kJ} \mathrm{mol}^{-1}\right)\end{array}$ & $\mathrm{R}^{2}$ & $\chi^{2}$ & $\begin{array}{l}\mathrm{A}_{\mathrm{T}} \\
\text { (e) }\end{array}$ & $\begin{array}{l}\mathrm{b}_{\mathrm{T}} \\
\text { (f) }\end{array}$ & $\mathrm{R}^{2}$ \\
\hline 0.109 & 0.113 & 1756.63 & 0.995 & 0.0002 & 6.01 & 0.142 & 0.685 & 0.127 & $5.1 \times 10^{-09}$ & 9.905 & 0.836 & 0.0028 & 34.36 & 196.68 & 0.734 \\
\hline
\end{tabular}

Units: (a): $\mathrm{mmol} \mathrm{g}^{-1}$; (b): $\mathrm{L} \mathrm{mmol}^{-1}$; (c): $\mathrm{mmol} \mathrm{g}^{-1}\left(\mathrm{~L} \mathrm{mmol}^{-1}\right)^{1 / \mathrm{n}}$; (d): $\mathrm{J}^{2} \mathrm{~mol}^{-2}$; (e): $\mathrm{kJ} \mathrm{mol}^{-1}$; (f): $\mathrm{L} \mathrm{mol}^{-1}$. 


\subsubsection{Influence of temperature}

It is important to investigate the effect of temperature on adsorption in a view of practical application. The adsorption experiments were carried out at six different temperatures including 293, 298, 303, 308, 313 and $318 \mathrm{~K}$. The adsorption capacity slightly increases from 0.0912 to $0.0997 \mathrm{mmol} \mathrm{g}^{-1}$ with the increase in the temperature from 293 to $318 \mathrm{~K}$. This behavior confirms that the adsorption process of CV onto MAlg is endothermic. This observation can be attributed to increasing of the mobility of the dye molecules and rate of diffusion of adsorbate molecules across the surface of adsorbent with increasing temperature, which leads to an increase in the adsorption capacity [50]. The adsorption equilibrium constant, $\mathrm{K}_{\mathrm{c}}$ was determined (Eq. 8) and used with the van't Hoff equation (Eq. 11) and conventional thermodynamic equation (Eq. 10) for evaluating the thermodynamic constants of the sorbents (i.e., the standard enthalpy change, $\Delta \mathrm{H}^{\mathrm{o}}$, the standard free Gibbs energy, $\Delta \mathrm{G}^{\mathrm{o}}$, and the standard entropy change, $\Delta \mathrm{S}^{\mathrm{o}}$ ).

$\mathrm{K}_{\mathrm{c}}=\frac{q_{e}}{C_{e}}$

where $\mathrm{q}_{\mathrm{e}}$ and $\mathrm{C}_{\mathrm{e}}$ are equilibrium concentrations of $\mathrm{CV}$ on the adsorbent and in the solution, respectively.

$\Delta \mathrm{G}^{\mathrm{o}}=-\mathrm{RT} \ln \mathrm{K}_{\mathrm{c}}$

$\Delta \mathrm{G}^{\mathrm{o}}=\Delta \mathrm{H}^{\mathrm{o}}-\mathrm{T} \Delta \mathrm{S}^{\mathrm{o}}$

Therefore the van't Hoff equation becomes:

$\ln K_{\mathrm{C}}=\frac{-\Delta \mathrm{H}^{\circ}}{\mathrm{RT}}+\frac{\Delta \mathrm{S}^{\circ}}{\mathrm{R}}$

The value of standard enthalpy change $\left(\Delta \mathrm{H}^{0}\right)$ and standard entropy change $\left(\Delta \mathrm{S}^{0}\right)$ for the adsorption process are thus determined from the slope and intercept of the plot of $\operatorname{lnK}_{\mathrm{c}} v s .1 / \mathrm{T}$ (Figure SM7, see Supplementary Material Section): the values of thermodynamic parameters are reported in Table 3. The positive value of $\Delta \mathrm{H}^{\mathrm{o}}$ confirms the endothermic nature of adsorption process. The negative values of $\Delta \mathrm{G}^{\mathrm{o}}$ indicate that the adsorption reaction is spontaneous. The increase in the negativity of $\Delta \mathrm{G}^{\mathrm{o}}$ with increasing temperature confirms that 
the "favorability" increases with temperature. On the other hand, the positive value of the entropy change $\left(\Delta S^{0}\right)$ mean that the "disorder" of the system increases after dye adsorption.

Table 3: Standard enthalpy, entropy and free energy changes for CV adsorption

\begin{tabular}{|c|c|c|c|c|c|c|c|c|}
\hline \multirow[b]{2}{*}{$\left(\mathrm{kJ} \mathrm{mol}^{-1}\right)$} & $\Delta \mathrm{S}^{0}$ & \multirow{2}{*}{$\mathrm{T}_{0}(\mathrm{~K})$} & \multicolumn{6}{|c|}{$\Delta \mathrm{G}^{\mathrm{o}}\left(\mathrm{kJ} \mathrm{mol}^{-1}\right)$} \\
\hline & $\left(\mathrm{J} \mathrm{mol}^{-1} \mathrm{~K}^{-1}\right)$ & & $293 \mathrm{~K}$ & $298 \mathrm{~K}$ & $303 \mathrm{~K}$ & $308 \mathrm{~K}$ & $313 \mathrm{~K}$ & $318 \mathrm{~K}$ \\
\hline 115.9 & 414.19 & 279.82 & -5.45 & -7.52 & -9.59 & -11.67 & -13.74 & -15.81 \\
\hline
\end{tabular}

In industries and water purification plants the optimum temperature at which the adsorption is highly feasible and spontaneous is essential. The adsorption of dyes onto adsorbent surfaces may be either spontaneous or non-spontaneous in function of temperature. The limit temperature value corresponding to a null value of standard free energy can thus be deduced from Eq. 12. The range of temperature can be predicted from the value of temperature at which the standard free energy is zero $\left(\mathrm{T}_{0}\right)$, and then the minimal temperature for the process to being spontaneous.

$$
\mathrm{T}_{0}=\frac{\Delta \mathrm{H}^{\circ}}{\Delta \mathrm{S}^{\circ}}
$$

Here, the calculated value of zero standard free energy temperature $\left(\mathrm{T}_{0}\right)$ is $279.8 \mathrm{~K}$. The low $\mathrm{T}_{0}$ values indicate the feasibility of $\mathrm{CV}$ removal at very low temperature by the studied adsorbents.

\subsubsection{Effect of adsorbent dosage}

The adsorption of $\mathrm{CV}$ on the MAlg sorbent was studied by changing the quantity of adsorbent range of 0.01 to $0.1 \mathrm{~g}$ of sorbent for $25 \mathrm{~mL}$ dye solution, with the dye concentration of $2 \times 10^{-4} \mathrm{M}$ at $298 \pm 1 \mathrm{~K}$ and $\mathrm{pH}$ of 7.0. The results in Figure 6a show the CV adsorption capacity as a function of adsorbent amount. It has been found that the adsorption capacity decreases from 0.426 to $0.045 \mathrm{mmol} \mathrm{g}^{-1}$ when the dose of MAlg increases from 0.01 to $0.1 \mathrm{~g}$ for $25 \mathrm{~mL}$ dye solution. Figure $6 \mathrm{~b}$ shows the effect of dose on the equilibrium concentration 
$\left(\mathrm{C} / \mathrm{C}_{0}\right)$ of $\mathrm{CV}$ by the MAlg sorbent. As the dose increases, the equilibrium concentration of $\mathrm{CV}$ is decreased, which is due to the increase in the adsorbent surface area of the adsorbent. The results shown indicate that the removal efficiency increases up to $99.74 \%\left(\mathrm{C} / \mathrm{C}_{0}=\right.$ 0.0025 ) at adsorbent dose of $0.1 \mathrm{~g} / 25 \mathrm{~mL}$. The surface of the adsorbent is composed of active sites with a spectrum of binding energies [45]. At the low dose of adsorbent, all of the sites are exposed entirely and the adsorption on the surface is saturated faster showing a higher adsorption capacity. An increase in the mass of adsorbent leads to a decrease in equilibrium adsorption capacity per unit weight of the adsorbent $\left(\mathrm{q}_{\mathrm{e}}\right)$ because there are excess adsorbent for the limited amount of $\mathrm{CV}$ ions in the solution. According to the result, the adsorbent dose of $0.01 \mathrm{~g} / 25 \mathrm{~mL}$ dye solution will achieve the maximum loading capacity for the adsorbent, and the dose of $0.1 \mathrm{~g} / 25 \mathrm{~mL}$ will achieve the maximum removal efficiency $99.74 \%\left(\mathrm{C} / \mathrm{C}_{0}=\right.$ 0.0025). So the determination of the optimum adsorbent dose depends on the design and purpose of treatment process. Thus if the water quality standard set by WHO is the target, a larger amount of adsorbent is better $(0.1 \mathrm{~g} / 25 \mathrm{~mL})$, and if the maximum loading of the sorbent per unit mass is the target, the dose of $0.01 \mathrm{~g} / 25 \mathrm{~mL}$ is more suitable. 

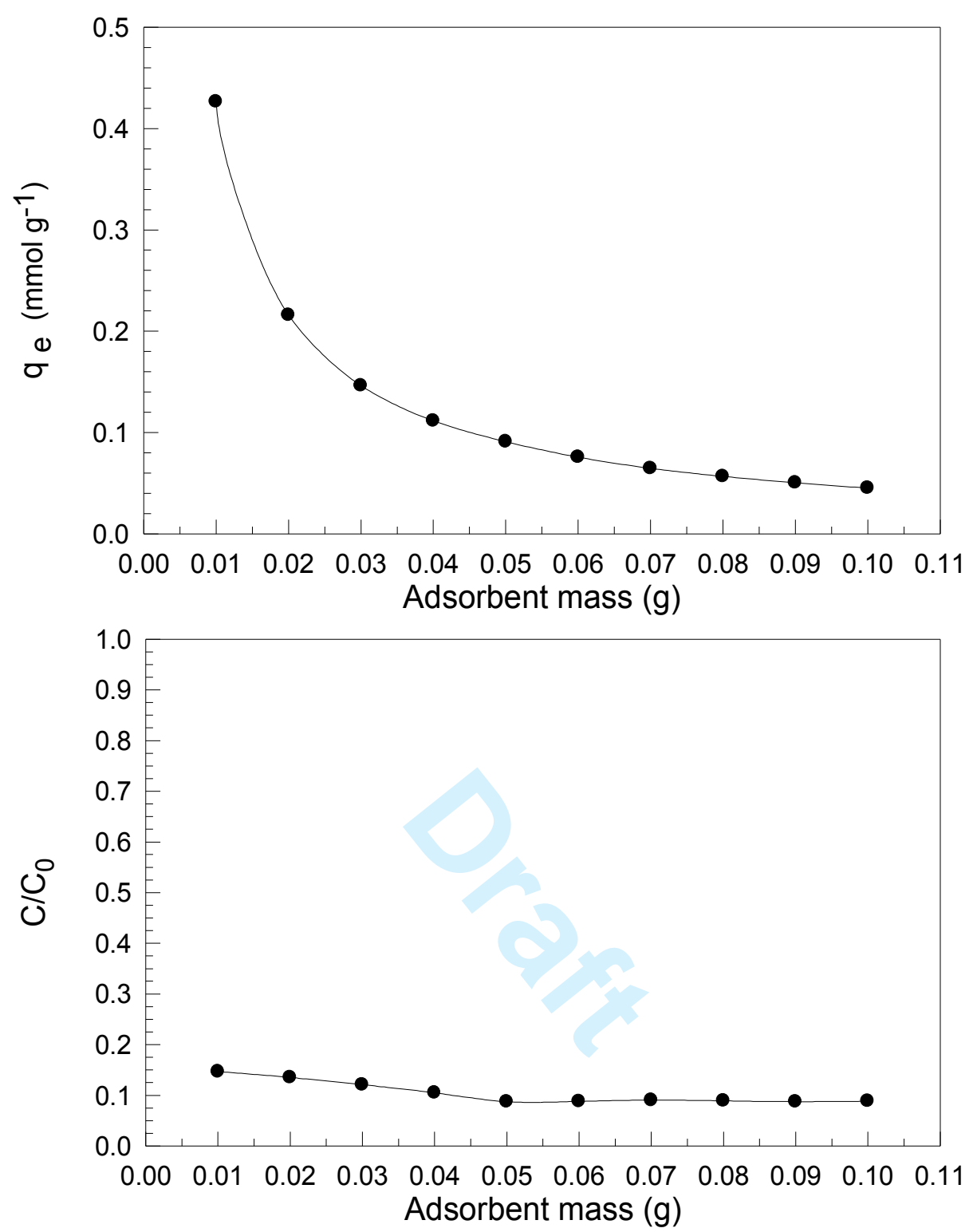

Figure 6: Effect of sorbent dose (SD) on CV adsorption using MAlg: (a) sorption capacity $v s$.

$\mathrm{SD}$, (b) relative residual concentration $\left(\mathrm{C} / \mathrm{C}_{0}\right)$ vs. $\mathrm{SD}\left(\mathrm{C}_{0}: 2 \times 10^{-4} \mathrm{M} ; \mathrm{T}: 298 \pm 1 \mathrm{~K}\right.$; $\mathrm{pH} 7)$.

\subsection{Adsorbent regeneration}

Regeneration of the sorbent were performed by placing $0.5 \mathrm{~g}$ of composite in the flask and then washed carefully by flowing alkaline solution $(0.001 \mathrm{M} \mathrm{NaOH})$ then distilled water. The composite loaded by $\mathrm{CV}$ was then subjected for regeneration using $0.01 \mathrm{M} \mathrm{HCl}$. After regeneration the composite was again carefully washed with distilled water to become ready 
for the second run of uptake. The regeneration efficiency for each adsorption/desorption cycle was found to be $98.6,69.6,94.5 \%$. This indicates that composite has good performance for repeated use up to at least 3 cycles.

In order to identify adsorbent stability in acidic solution (Partial magnetite leaching), the concentration of Iron in the eluent solution $(\mathrm{HCl})$ was analyzed by spectrophotometry (Hach $\mathrm{DR} / 5000$ ) for total iron concentration (adapted from standard Methods for the Examination of Water and Wastewater). The release of Iron from the adsorbent was negligible at $\mathrm{pH}$ close to 1.7; the fraction of iron leached from the sorbent did not exceed $0.2 \%$.

\subsection{Comparison of adsorption of $\mathrm{CV}$ dye with various sorbents}

Table 4 shows the comparison of maximum sorption capacities of the MAlg with a series of values found in the literature (together with the best operating conditions reported by respective authors). A direct comparison of sorption performance is difficult due to different experimental conditions; however, this is a useful criterion for roughly evaluating the potential of these materials. The MAlg adsorbent has a adsorption capacity of the same order of magnitude as other sorbents; although the carboxylate functionalized sugarcane bagasse with Meldrum's acid (SMA) adsorbent [51], $\mathrm{CaFe}_{2} \mathrm{O}_{4}$ magnetic nanoparticles [52], clay/poly(N-isopropylacrylamide) (PNIPAm) nanocomposite (CPN) hydrogels [53], coreshell $\mathrm{SiO}_{2} @ \mathrm{MgO}$ [54], and $\mathrm{SnFe}_{2} \mathrm{O}_{4} @$ activated carbon magnetic nanocomposite [55], showed better adsorption capacity. It is noteworthy that the MAlg sorbent has an important advantage related to their fast kinetics. The fast adsorption of $\mathrm{CV}$ dye reveals that MAlg adsorbent could be promising for practical application in CV dye removal from wastewater. 
Table 4: Comparison of sorption capacity for CV dye with various adsorbents

\begin{tabular}{|c|c|c|c|c|c|c|c|}
\hline Adsorbent material & $\begin{array}{c}\text { Initial } \\
\text { pH }\end{array}$ & $\begin{array}{c}\text { Contact } \\
\text { time (min) }\end{array}$ & $\begin{array}{c}\text { Temperature } \\
\text { (K) }\end{array}$ & $\begin{array}{c}\text { Initial } \\
\text { concentration } \\
(\mathrm{mg} / \mathrm{L})\end{array}$ & $\begin{array}{l}\text { Sorbent dosage } \\
\qquad\left(\mathrm{g} \mathrm{L}^{-1}\right)\end{array}$ & $\begin{array}{l}\text { Sorption capacity } \\
\qquad\left(\mathrm{mg} \mathrm{g}^{-1}\right)\end{array}$ & References \\
\hline $\begin{array}{l}\text { sugarcane bagasse modified with } \\
\text { Meldrum's acid (SMA) }\end{array}$ & 7.0 & 720 & 318 & 200 & 0.2 & 692.1 & {$[51]$} \\
\hline $\begin{array}{l}\mathrm{CaFe}_{2} \mathrm{O}_{4} \text { magnetic nanoparticles } \\
\text { (MNPs) }\end{array}$ & 5.5 & 30 & 298 & 30 & 0.05 & 10.67 & {$[52]$} \\
\hline $\begin{array}{l}\text { clay/poly(N-isopropyl acrylamide) } \\
\text { (PNIPAm) nanocomposite (CPN) } \\
\text { hydrogels }\end{array}$ & 3.0 & 720 & 298 & 10 & - & 1.2 & {$[53]$} \\
\hline $\mathrm{SiO}_{2} @ \mathrm{MgO}$ composite (SMC) & 6.5 & 300 & 318 & 500 & 0.4 & 2244.85 & {$[54]$} \\
\hline $\begin{array}{l}\mathrm{SnFe}_{2} \mathrm{O}_{4} @ \text { activated carbon } \\
\text { magnetic }\end{array}$ & 8.0 & 1440 & 323 & - & 0.1 & 158.73 & {$[55]$} \\
\hline Magnetite Alginate & 7 & 30 & 298 & 81.59 & 0.05 & 37.5 & [This work] \\
\hline
\end{tabular}




\section{Conclusion}

Magnetite alginate as a magnetic adsorbent for the removal of crystal violet from aqueous solutions, were successfully prepared by in situ co-precipitation method and characterized via FTIR, SEM, XRD and TGA. This adsorbent exhibited high adsorption capacity towards CV. The maximum monolayer adsorption capacities are $0.092 \mathrm{mmol} \mathrm{g}^{-1}$ at $\mathrm{pH} 7$ and $298 \mathrm{~K}$. The nature of interaction between the dye cations and the adsorbent was found to be dependent upon the Alkalinity of the medium. The adsorption process carries out by cation exchange mechanism; however the adsorbent maintained a significant adsorption capacity at alkaline pH. The adsorption isotherms are well fitted by the Langmuir equation. Uptake kinetics is correctly fitted by the pseudo-second order rate equation. The thermodynamic parameters have been determined: the reaction is endothermic, spontaneous. The randomness of the system increases with CV adsorption. Even under drastic conditions of high ionic strength, the sorbent maintained its high sorption capacity. The adsorbents can be used successfully up to 4 times without significant loss of its original efficiency regenerated by $0.01 \mathrm{M} \mathrm{HCl}$. This means that the studied sorbent is a promising sorbent for the efficient removal of CV dye from wastewater of textile industry. 


\section{References}

[1] El-Bindary, A. A.; M. A. Diab, Hussien, M. A.; El-Sonbati, A. Z.; Eessa, A. M. Spectrochim. Acta A 2014, 124, 70.

[2] Boruah, P. K.; Borthakur, P. G.; Darabdhara, Kamaja, C. K.; Karbhal, I.; Shelke, M. V.; Phukan, P.; Saikia, D.; Das, M. R. RSC Adv. 2016, 6, 11049.

[3] Li, S. Biores. Technol. 2010, 101, 2197.

[4] Pourjavadi, A.; Hosseini, S. H., Seidi, F.; Soleyman, R. Polym. Int. 2013, 62, 1038.

[5] He, H.; Yang, S.; Yu, K.; Ju, Y.; Sun, C.; Wang, L. J. Hazard. Mater. 2010, 173, 393.

[6] Taher, A.; Mohsin, M.; Farooqui, M.; Farooqui, M. J. Adv. Scient. Res. 2012, 3, 36.

[7] Sarma, G. K.; Gupta, S. S.; Bhattacharyya, K. G. J. Environ. Manage. 2016, 171, 1.

[8] Jain, S.; Jayaram, R.V. Desalination. 2010, 250, 921.

[9] Elwakeel, K. Z.; El-Bindary, A.A.; El-Sonbati, A.Z.; Hawas, A. M. RSC Adv. 2016, 6 3350 .

[10] Shojaat, R.; Saadatjoo, N.; Karimi, A.; Aber, S. J. Environ. Chem. Eng. 2016, 4, 1722.

[11] Ali, I.; Gupta, V. K. Nat. Protoc. 2007, 1, 2661.

[12] Subbaiah, M. V.; Kim, D. S. Ecotoxicol. Environ. Saf. 2016,128, 109.

[13] Lakshmipathy, R.; Sarada, N.C. Desalin. Water. Treat. 2016, 57, 10632.

[14] Al-Kahtani, A. A.; Abou Taleb M. F. J. Hazard. Mater. 2016, 309 10-19.

[15] Vaiano, V.; Iervolino, G.; Sannino, D.; Murcia, J.J.; Hidalgo, M.C.; Ciambelli, P.; Navío, J.A. Appl. Catal. B: Environ. 2016, 188, 134.

[16] Thangavel, S.; Thangavel, S.; Raghavan, N.; Krishnamoorthy, K.; Venugopal, G. J. Alloys Compd. 2016, 665, 107.

[17] Aravind, P.; Subramanyan, V.; Ferro, S.; Gopalakrishnan, R. Water Res. 2016, 93, 230.

[18] Benjwal, P.; Kar, K. K. RSC Adv. 2015, 5, 98166.

[19] Papic, S.; Koprivanac, N.; Bozic, A.L.; Metes, A. Dyes Pigm. 2004, 62, 291.

[20] Bouras, H. D.; Benturki, O.; Bouras, N.; Attou, M.; Donnot, A.; Merlin, A.; Addoun, F.; Holtz, M. D. J. Mol. Liq. 2015, 211, 1039.

[21] Baban, A.; Yediler, A.; Lienert, D.; Kemerdere, N.; Kettrup, A. Dyes Pigm. 2003, 58, 93.

[22] Xu, L.; Sun, Y.; Zhang, L.; Zhang, J.; Wang, F. Desalin. Water. Treat. 2016, 57, 8815.

[23] Ledakowicz, S.; Solecka, M.; Zylla, R. J. Biotechnol. 2001, 89, 175.

[24] Slejko; F.L. Adsorption Technology. A Step-by-step Approach to Process Evaluation and Application, Marcel Dekker, New York, 1985. 
[25] Liu, S.; Li, Y.; Li, L. Carbohyd. Polym. 2017, 160, 62.

[26] Mahdavinia, G. R.; Aghaie, H.; Sheykhloie, H.; Vardini, M.T.; Etemadi, H. Carbohyd. Polym 2013, 98, 358.

[27] Shirley, R. the CRYSFIRE system for automatic powder indexing:Users Manual, the lattice press, Guildford, Surrey GU 27NL, England, 2000.

[28] Srivastava, M.; Singh, J.; Yashpal, M.; Gupta, D.K.; Mishra, R.; Tripathi, S.; Ojha, A.K Carbohyd. Polym. 2012, 89, 821.

[29] Daemi, H.; Barikani, M.; Barmar, M. Carbohyd. Polym. 2013, 92, 490.

[30] Xiao, Q.; Tan, X.; Ji, L.; Xue, J. Synthetic Met. 2007, 157, 784.

[31] Fang, F. F.; Kim, J. H.; Choi, H. J. Polymer 2009, 50, 2290.

[32] Kalyani, S.; Smitha, B.; Sridhar, S.; Krishnaiah, A. Desalination 2008, 229, 68.

[33] Klug, H. P.; Alexander, L. E. X-ray Diffraction Procedures: For Polycrystalline and Amorphous Materials, 2nd ed., Wiley-Interscience, New York, 1974.

[34] Inbaraj, B.S.; Chiu, C.; Ho, G. J. Yang, B. Chen, J. Hazard. Mater. 2006, 137, 226.

[35] Wang, L.; Zhang, J.; Wang, A. Desalination 2011, 266, 33.

[36] Goh, C. H.; Heng, P. W. S.; Chan, L. W. Carbohyd. Polymer 2012, 88, 1.

[37] Mahdavinia, G.R.; Bazmizeynabad, F.; Seyyedi, B. Desalin. Water. Treat. 2015, 53, 2529.

[38] Gholami, M.; Vardini, M. T.; Mahdavinia, G. R. Carbohyd. Polymer 2016, 136, 772.

[39] Elwakeel, K. Z.; Guibal, E. Carbohyd. Polymer 2015,134, 190.

[40] Lagergren S. Kungliga Swenska Vetenskapsakademiens Handlingar 1898, 24, 1.

[41] Ho, Y. S.; McKay, G. Process Biochem. 1999, 34, 451.

[42] Weber, W. J.; Morris; J. C. J. Sanit. Eng. Div. ASCE 1963, 89, 31.

[43] Zeldowitsch; J. Acta Physicochim. URSS 1934, 1, 364.

[44] Elwakeel, K. Z.; Alrekaby, M. M. J. Hazard. Mater. 2011, 188, 10.

[45] Elwakeel, K. Z.; Guibal, E. Chem. Eng. J. 2015, 281, 345.

[46] Langmuir, I. J. Am. Chem. Soc. 1918, 40, 1361.

[47] Freundlich, H. M. F. Z. Phys. Chem. 1906, 57A, 385.

[48] Dubinin, M. M.; Zaverina, E. D.; Radushkevich, L.V. Zh. Fiz. Khim. 1947, 21, 1351.

[49] Temkin, M. I.; Pyzhev, V. Acta physiochim. URSS 1940, 12, 217.

[50] Patra, A. S.; Ghorai, S.; Ghosh, S.; Mandal, B.; Pal, S. J. Hazard. Mater. 2016, 301, 127.

[51] Ferreira, B. C. S.; Teodoro, F. S.; Mageste, A. B. Ind. Crops Prod. 2015, 65, 521.

[52] An, S.; Liu, X.; Yang, L.; Zhang, L. Chem. Eng. Res. Design, 2015, 94, 726-735. 
[53] Zhang, Q.; Zhang, T.; He, T.; Chen, L. Appl. Clay Sci. 2014, 90, 1.

[54] Pei, Y.; Wang, M.; Tian, D.; Xu, X.; Yuan, L. J. Colloid. Interf. Sci. 2015, 453, 194.

[55] Rai, P.; Gautam, R. K.; Banerjee, S.; Rawat, V.; Chattoapadhyaya, M. C. J. Environ. Chem. Eng. 2015, 3, 2281. 